Artigo original

Hegemonia - Revista Eletrônica do Programa de Mestrado em Direitos Humanos, Cidadania e Violência/Ciência Política do Centro Universitário Unieuro

ISSN: 1809-1261

UNIEURO, Brasília, número 29, Janeiro a Junho de 2020, pp. 62-84.

Recebido em: 12/6/2019

Avaliado em: 23/9/2019

Aprovado em: 12/11/2019

\title{
POLÍTICAS PÚBLICAS E A LUTA DEMOCRÁTICA PELA CIDADANIA, NO BRASIL
}

Delmo Arguelhes ${ }^{1}$ e Vicente Fonseca ${ }^{2}$

Resumo: Este artigo tem como foco principal mostrar os melhores caminhos para o sucesso da luta democrática, tendo como base a implementação de Políticas Públicas, que possam promover novas técnicas e modelos de ações políticas, que ajudem a consolidar a cidadania de forma equânime e com equidade, no Brasil contemporâneo. Para tanto, iremos estudar também, como se deu o processo de institucionalização dos direitos humanos em nosso país, como este processo vem ajudando a consolidar o sentimento de liberdade e igualdade e quais os são pressupostos básicos para o favorecimento do pleno exercício da cidadania. Neste contexto, vamos analisar como as políticas públicas são implementadas em face às demandas sociais, postas pela exigência do cumprimento de um estado democrático de direitos.

Palavras-chave: Cidadania, Políticas Públicas, Direitos Humanos, Estado Democrático de Direito, Democracia

Abstract: This article has as its main focus to show the best ways for the success of the democratic struggle, based on the implementation of Public Policies, which can promote new techniques and models of political actions that help to consolidate citizenship in an equitable and equitable way. in contemporary Brazil. To this end, we will also study how the process of institutionalization of human rights in our country took place, how this process has been helping to consolidate the feeling of freedom and equality and what are the basic assumptions for the promotion of the full exercise of citizenship. In this context, we will analyze how public policies are implemented in the face of social demands, demanded by the fulfillment of a democratic state of rights.

Keyword: Citizenship, Public Policy, Human Rights, Democratic Rule of Law, Democracy.

Introdução

Inicialmente vamos tentar esclarecer para a sociedade civil organizada alguns conceitos primordiais para a obtenção da coexistência pacífica, numa sociedade tão desigual como a do Brasil.

\footnotetext{
${ }^{1}$ Doutor em História e docente do Centro Universitário Unieuro.

${ }^{2}$ Doutor em Ciência Política e docente do Centro Universitário Unieuro.
} 
Artigo original

Hegemonia - Revista Eletrônica do Programa de Mestrado em Direitos Humanos, Cidadania e Violência/Ciência Política do Centro Universitário Unieuro

ISSN: $1809-1261$

UNIEURO, Brasília, número 29, Janeiro a Junho de 2020, pp. 62-84.

O primeiro passo será o de apresentar uma metodologia científica que promova a curto e médio prazo uma melhora significativa da qualidade da democracia e aprimore de forma equânime a cidadania. Por outro lado, vamos buscar novos elementos que facilitem o entendimento por todos os cidadãos, dos mecanismos técnicos e políticos a serem usados, visando o aprimoramento da formação acadêmica daqueles que se interessam pelo bem-estar da humanidade, tendo como exemplo o nosso país.

Então, vamos provocar a curiosidade dos nossos leitores, perguntando: Qual é a importância para a sociedade se implementar Políticas Públicas Transparentes? O que significa Democracia para os menos privilegiados? O que são Direitos Humanos? Que dimensões assumem a conquista dos direitos humanos no Brasil? O que é cidadania? Como entender o seu processo de construção nas sociedades modernas, em particular nas sociedades pós-coloniais? Como se deu a conquista da cidadania nos Estados-nação? E nos países americanos, com o processo escravocrata instituído, como a cidadania foi definida? Que razões justificam a negação da cidadania que se mantivera com a exploração do trabalho servil? E, nos governos de regime ditatoriais, o que significou a dimensão direitos humanos em sua acepção mais ampla do termo? No contexto atual brasileiro, estado de princípios democráticos, que políticas públicas se destinam ao reconhecimento dos direitos sociais, em particular de o direito de igualdade? Em que medida, essas políticas públicas são eficazes à garantia desses direitos sociais às minorias?

A partir deste conjunto de questionamentos, pretendemos neste artigo, ainda que de maneira bastante tímida, identificar alguns elementos acerca do surgimento dos direitos humanos e suas dimensões históricas de sentido, com destaque para a extensão da titularidade aos sujeitos de direitos; o conceito de cidadania e como se deu o seu processo de construção no Brasil, bem como trazer à discussão a análise de políticas públicas brasileiras destinadas às demandas reivindicatórias dos grupos sociais minoritários. Nessa reflexão, também se vislumbra direcionar o nosso olhar sobre a eficácia na implantação de tais políticas que possibilite oportunidades iguais às futuras gerações no Brasil.

Para tanto, recorre-se à literatura que registra e nos permite observar a evolução histórica da cidadania no Brasil, a instituição dos direitos humanos, o sentido de liberdade e igualdade que foram se instalando no seio da sociedade brasileira, a partir das lutas e conquistas dos grupos sociais por um estado democrático de direito.

Alguns estudos apontam que a conquista dos direitos no Brasil foi um processo lento, haja vista o longo período escravagista que perdurou em nosso país. E, mesmo após a abolição da 
Artigo original

Hegemonia - Revista Eletrônica do Programa de Mestrado em Direitos Humanos, Cidadania e Violência/Ciência Política do Centro Universitário Unieuro

ISSN: $1809-1261$

UNIEURO, Brasília, número 29, Janeiro a Junho de 2020, pp. 62-84.

escravatura, parte população brasileira continua excluída do pleno exercício da cidadania, sem a garantia de alguns direitos sociais, por exemplo, mesmo que juridicamente estivesse liberta.

Inicialmente, considera-se interessante fazer referência à concepção de alguns termos e categorias de análise que iremos utilizar nesta reflexão. A expressão direitos bumanos, no entendimento de DALLARI (2004:12) remete à compreensão do que sejam os direitos fundamentais da pessoa humana. Então, tudo a que se refere ao ser humano e pressupõe a sua condição de existência, na sua singularidade, em tudo a que ela necessita como fundamental para participar plenamente da vida. Assim, o define como [...] "conjunto de condições e de possibilidades associada às características naturais dos seres humanos, a capacidade natural de cada pessoa e os meios de que a pessoa pode valer-se como resultado da organização social”".

Com relação à construção e o entendimento do conceito de história da cidadania, que sofre variações de sentido através dos tempos o que nos permite observar as peculiaridades e nuances desse termo, na atualidade, pressupõem ação e o seu exercício é condição de ser do indivíduo.

Ou seja, o cidadão é aquele que possui e goza determinados direitos. Ter direitos significa ter a capacidade e autonomia para usufruir determinados benefícios legais garantidos pelo Estado aos seus habitantes.

\section{O Berço Histórico da cidadania}

A noção de cidadania remonta à Antiguidade, teve suas origens na Grécia e Roma antigas. Grécia Antiga era formada por Cidades-Estado autônomas, conhecidas como Polis.

Não se objetiva aqui discorrer sobre o funcionamento de uma Cidade-Estado grega, até porque essa ideia difere muito do seu uso nas sociedades contemporâneas, porém, ressalta-se a origem dessa expressão por ser um termo utilizado até hoje.

Em algumas das Cidades-Estado vigorava a democracia direta, regime político no qual os cidadãos, chamados de politai, homens livres participavam das decisões do governo na cidade por meio de assembleias.

Poucos eram os indivíduos que tinham acesso a uma cidadania plena. Somente aqueles que eram homens gregos, adultos e proprietários de terras é que detinham o poder de decidir sobre os rumos da cidade. Os pobres, as mulheres, os estrangeiros, os jovens, os escravos estavam excluídos do direito à cidadania grega. 
Artigo original

Hegemonia - Revista Eletrônica do Programa de Mestrado em Direitos Humanos, Cidadania e Violência/Ciência Política do Centro Universitário Unieuro

ISSN: $1809-1261$

UNIEURO, Brasília, número 29, Janeiro a Junho de 2020, pp. 62-84.

Aristóteles, filósofo grego, atribui o termo cidadão às pessoas que podiam participar da atividade política e social da cidade. Diz que: '[...] um cidadão integral pode ser definido pelo direito de administrar justiça e exercer funções públicas'. (ARISTÓTELES, 1997:78). Assim ainda expressa:

Cidadão, de um modo geral, é uma pessoa que participa das funções de governo e é governado, embora ele seja diferente segundo cada forma de governo; em relação à melhor forma, cidadão é uma pessoa dotada de capacidade e vontade de ser governada e governar com vistas a uma vida conforme ao mérito de cada um. (Aristóteles, 1997:194).

$\mathrm{Na}$ Roma Antiga, essa ideia de cidadania também era característica marcante nessa sociedade, aonde somente aqueles que eram considerados nobres - os patrícios- acumulavam direitos (a propriedade da terra e o usufruto do poder político). Os não-nobres, denominados plebeus, necessitaram provocar revoltas contra o poder constituído, para que tivessem acesso a alguns direitos.

Embora ainda se versasse de um modelo de cidadania restrita, segundo os historiadores, o fato dos plebeus terem conseguido o acesso a alguns direitos já faz de Roma uma sociedade mais aberta que a aristocrática Grécia.

Com a queda do Império Romano, em 476, desapareceu o conceito de cidadania na Europa. Durante a Idade Média não havia cidadãos. A nobreza feudal tinha servos da gleba, a Igreja tinha os comungantes, e o rei vassalos e súditos. De forma que somente após mais de mil anos os conceitos de cidadão e cidadania foram resgatados, voltam a ocupar um lugar central na vida política.

A Assembleia Constituinte, que emergiu da Revolução Francesa de 1789, foi um marco para a história dos direitos e da cidadania. A nova constituição, elaborada pelos revolucionários, intitulada Declaração Universal dos Direitos do Homem e do Cidadão, afirmava, entre outros aspectos, que todos são iguais perante a lei.

Era a formação de uma nova sociedade, em oposição ao "Antigo Regime" (Ancien Régime), no qual os direitos eram privilégios somente da nobreza e clero.

No entanto, esses direitos não se estendiam a toda à população. Trata-se de uma 'revolução burguesa', em que uma classe social em ascensão e de domínio economicamente forte, passava a adquirir o poder político e governar a nação francesa, e que como consequência configura ter mais direitos que o restante do povo trabalhador. Isso fica evidenciado nas etapas 
Artigo original

Hegemonia - Revista Eletrônica do Programa de Mestrado em Direitos Humanos, Cidadania e Violência/Ciência Política do Centro Universitário Unieuro

ISSN: $1809-1261$

UNIEURO, Brasília, número 29, Janeiro a Junho de 2020, pp. 62-84.

dessa revolução que mostram o quanto a luta pelos direitos dos indivíduos foi uma constante e que custaram muitas vidas.

Os registros confirmam que na maior parte do tempo a alta burguesia exerceu o poder um exemplo clássico dessa dinâmica foi a criação do voto censitário para ter o direito de eleger os governantes da nação, ou seja, um direito de quem tinha determinada renda e propriedades.

De forma que, a Revolução Francesa, bem como as revoluções que a antecederam, as Revoluções Inglesas, no século XVII, e a Americana, também no século XVIII, forneceram a base da cidadania nas sociedades contemporâneas.

Inspiradas nas ideias iluministas, tanto a Declaração dos Direitos do Homem e do Cidadão como a primeira Constituição francesa concentraram esforços para que os direitos e as garantias individuais fossem incorporados à vida de um número maior de indivíduos, conferindolhes cidadania. Ou seja, quando essa perspectiva se constitui em o Estado de direito (que protege indivíduos e cidadãos).

Como termo político, cidadania significa exercício de direitos, compromisso ativo, participação política, responsabilidade. Assim, significa participar da vida na sociedade, no país. Sem a cidadania não pode haver aquele compromisso responsável que garante o respeito aos direitos humanos e democráticos.

Para DALLARI (2004:22) a noção de cidadania busca expressar a igualdade entre os homens. Afirma em suas palavras

A cidadania expressa um conjunto de direitos que dá à pessoa a possibilidade de participar ativamente da vida e do governo de seu povo. Quem não tem cidadania está marginalizado ou excluído da vida social e da tomada de decisões, ficando numa posição de inferioridade dentro do grupo social.

Herbert de Souza, o Betinho, um dos mais respeitados sociólogos brasileiros, defensor incansável da cidadania e dos direitos dos menos favorecidos, define o termo em

[...] Cidadania é a consciência de direitos democráticos, é a prática de quem está ajudando a construir valores e as práticas democráticas. No Brasil, cidadania é fundamentalmente a luta contra a exclusão social, contra a miséria, é mobilização concreta pela mudança do cotidiano e das estruturas que beneficiam uns e ignoram milhões de outros. É querer mudar a realidade a partir da ação com os outros, da elaboração de propostas, da crítica, da solidariedade e da indignação com o que ocorre entre nós. E o cidadão é o indivíduo que tem consciência de seus direitos e deveres e participa ativamente de todas as questões da sociedade. Um cidadão com 
Artigo original

Hegemonia - Revista Eletrônica do Programa de Mestrado em Direitos Humanos, Cidadania e Violência/Ciência Política do Centro Universitário Unieuro

ISSN: $1809-1261$

UNIEURO, Brasília, número 29, Janeiro a Junho de 2020, pp. 62-84.

sentido ético forte e consciência de cidadania não abre mão desse poder de participação. (Souza apud Nunes, 2000, p. 5).

Para o cientista político italiano Norberto Bobbio (1909-2006), o direito do cidadão é a conversão universal dos direitos do ser humano. Por extensão, a efetiva cidadania é um privilégio das sociedades democráticas. Todavia, em regimes sob a forma de ditadura, autoritários, fechados e que não primam pelas liberdades de locomoção e de opinião não há cidadãos e, tampouco cidadania.

Por outro lado, para ser cidadão que desempenha a plena cidadania por si só não basta a existência de um regime democrático político-representativo, com direitos políticos e soberania popular respeitados; faz-se necessário que na sociedade prevaleça a democracia socialparticipativa, ou seja, os direitos sociais estendidos a todos os indivíduos daquela sociedade e não apenas privilégio de alguns.

Com relação à ideia de direitos humanos, os paradoxos que a acompanham têm mostrado controvérsias em variada compreensão de sentido. Em cada contexto histórico se apresenta de uma forma e ganha dimensões diversas de acordo com as práticas sociais.

A proclamação da Declaração Universal dos Direitos Humanos de 1948 traz como pressuposto à condição de igualdade de direito a todos os seres humanos. Reza em seu artigo I que "todos os homens nascem livres e iguais em dignidade e direitos. São dotados de razão e consciência e devem agir em relação uns aos outros com espírito de fraternidade”.

Contudo, o processo histórico das sociedades modernas tem demonstrado que tal princípio não figura em sua prática social o sentido pleno da expressão. Para algumas concepções teóricas sobre os direitos humanos não deve se restringir e ficar preso apenas a essa fórmula de igualdade perante a lei.

Considera-se esse sentido uma dimensão vaga, abstrata; uma igualdade restrita e de cunho formal. Nesse sentido, BOBBIO (2004: 65) elucida essa interpretação quando afirma:

Essa universalidade (ou indistinção, ou não-discriminação) na atribuição e no eventual gozo dos direitos de liberdade não vale para os direitos sociais, e nem mesmo para os direitos políticos, diante dos quais os indivíduos são iguais só genericamente, mas não especificamente. Com relação aos direitos políticos e aos direitos sociais, existem diferenças de indivíduo para indivíduo, ou melhor, de grupos de indivíduos para grupos de indivíduos, diferenças que são até agora (e $\mathrm{o}$ são intrinsicamente) relevantes. 
Artigo original

Hegemonia - Revista Eletrônica do Programa de Mestrado em Direitos Humanos, Cidadania e Violência/Ciência Política do Centro Universitário Unieuro

ISSN: 1809-1261

UNIEURO, Brasília, número 29, Janeiro a Junho de 2020, pp. 62-84.

Nessa interpretação, portanto, o valor da igualdade merece ser repensado, a fim de que as diferenças entre os indivíduos sejam observadas e respeitadas. Dessa forma, a afirmação ganha uma dimensão de sentido de acordo com suas especificidades e particularidades.

\subsection{Estudo sobre a cidadania no Brasil}

Em conformidade com o pensamento de GUIMARÃES (2012), a construção do conceito de cidadania no Brasil está intimamente ligada ao sentimento de liberdade, uma trajetória de obstáculos que seguiu longo e tortuoso caminho, da independência de Portugal, em 1822, aos dias de hoje.

Antes, porém, de adentrarmos as peculiaridades da nossa história humana, considera-se interessante enfatizar a ideia moderna de cidadania, proposta por T. H. Marshall (1976, apud Carvalho 2010) que a classifica em dimensões, a partir da garantia dos direitos civis, políticos e sociais [grifos nossos].

O referido teórico destaca que a cidadania na Inglaterra se desenvolveu em processo gradual lento e seguiu um percurso distinto de outros países como a França, a Alemanha, os Estados Unidos.

Historicamente, os direitos civis foram os primeiros a surgir, como produto do esfacelamento da hierarquia social que caracterizava as monarquias europeias até os séculos XVIII e XIX.

GUIMARÃES (2012) também enfatiza a ideia de Marshall sobre o modelo da Inglaterra e observa que desde o século XVIII, teria acontecido uma 'ampliação progressiva' da cidadania. Assim define que primeiro, no século XVIII, teriam se constituído os direitos civis, relacionados à liberdade individual e às relações de trabalho.

A partir do começo do século XIX, listas de direitos civis básicos passaram a fazer parte de todas as constituições liberais. É no século XIX, também, que a cidadania passou a abarcar os direitos políticos, ou seja, os cidadãos passaram a ter participação no processo político-decisório do Estado.

No Brasil, CARVALHO (2010), destaca que a instituição dos direitos sociais, diferentemente do contexto europeu já mencionado, qual seja a Inglaterra estudada por Marshall, precedem os outros direitos, dada a natureza complexa e histórica da construção do 'fenômeno da cidadania', a que o autor chama de Estado-nação. 
Artigo original

Hegemonia - Revista Eletrônica do Programa de Mestrado em Direitos Humanos, Cidadania e Violência/Ciência Política do Centro Universitário Unieuro

ISSN: $1809-1261$

UNIEURO, Brasília, número 29, Janeiro a Junho de 2020, pp. 62-84.

No que diz respeito à história de formação dos Estados independentes, ainda em GUIMARÃES (2012) ressalta a importância das revoluções modernas (tanto a Revolução Americana de 1776, como as guerras de Independência das colônias portuguesas e espanholas, no século XIX) para a sua constituição.

Muito embora esses Estados, separados das metrópoles a que pertenciam, por um bom período não apresentavam condições de instituírem-se Estados-nação na perspectiva inclusiva, com extensão da igualdade de direitos a todos os seus habitantes e garantia da unidade nacional em razão do modelo opressor escravocrata a que foram submetidos.

Sobre o contexto brasileiro, o processo de construção da cidadania passa por duas etapas distintas, a saber: a abolição do regime escravocrata (que foi a face mais cruel de uma sociedade marcada pela extrema desigualdade) e a ideia de sentimento nacional. Este último se constitui a partir do momento em que os direitos e garantias fundamentais dos cidadãos fossem estendidos a toda a sua população.

Do nosso ponto de vista, considera-se interessante destacar alguns desdobramentos e nuances das dificuldades encontradas na evolução histórica da cidadania e que levaram o nosso país ao retardamento e construção do sentido de liberdade a partir do estado de direito.

O fim da escravidão, em 1888, e a Proclamação da República, no ano subsequente, não provocaram qualquer tipo de alteração no quadro social por igualdade de condições e direitos de cidadãos.

A proibição do voto do analfabeto, por exemplo, manteve a maior parte da população pobre excluída de direitos políticos. Destarte, o poder político local continuou nas mãos dos grandes proprietários de terras — os latifundiários - até praticamente 1930.

Em relação a esse período da nossa história, costumava-se dizer que era a 'república dos coronéis, uma vez que o acesso aos cargos públicos, o controle do voto e o direito de eleger os governadores e presidente da República eram de controle de um grupo social específico.

É curioso também e vale a pena ressaltar que os direitos políticos em nosso país tiveram pouca duração, já que em 1937, a ditadura do Estado Novo, implantada por Vargas, perdura por toda a segunda República a ideia de Estado autoritário.

O cientista social Wanderley Guilherme dos Santos apud GUIMARÃES (2012) cunha o termo 'cidadania regulada' para se referir a esse período ditatorial do Estado Novo.

Embora alguns estudiosos considerem esse momento um paradoxo, vez que reconhecem que foi durante o governo de Vargas (1930-1945) que foi introduzida uma legislação social, que 
Artigo original

Hegemonia - Revista Eletrônica do Programa de Mestrado em Direitos Humanos, Cidadania e Violência/Ciência Política do Centro Universitário Unieuro

ISSN: $1809-1261$

UNIEURO, Brasília, número 29, Janeiro a Junho de 2020, pp. 62-84.

atingiu principalmente os centros urbanos. No modelo urbano os conflitos entre capital e trabalho se ancoram nas leis sindicais, trabalhistas e previdenciárias.

Após a Constituição de 1988, apelidada de 'cidadã', por garantir de forma extensa algumas das principais reivindicações dos movimentos sociais que tinham eclodido no país a partir de 1979, representa um ganho para a sociedade brasileira.

2. A Implementação e Análise correta de Políticas Públicas, voltadas para os menos favorecidos no Brasil

Quem se beneficia das políticas públicas? Em que medida a sua implantação atende as necessidades dos grupos reivindicatórios e em que grau de satisfação corresponde aos anseios da população interessada?

Como já ressaltado nessa discussão, muitos foram os percursos em que a história brasileira registra as lutas dos grupos sociais menos favorecidos, na dinâmica de conquistas de seus direitos e condições ao exercício de sua cidadania.

Nesse processo de construção e garantia da igualdade de direitos como cidadãos, fazemse presentes ao debate as questões de cunho racial, as relações de gênero em uma sociedade marcada pelo domínio do patriarcado e sexismo, a luta pela redemocratização da escola pública, bem como a luta pelo respeito e valorização à diversidade cultural, entre outras.

Nesse cenário de disparidades e injustiças, destaca-se o nebuloso e cruel sistema de escravização da população negra em nosso país.

Marcado por um quadro social de desigualdades, a história brasileira também assinala momentos marcantes das retóricas de inclusão social dos negros na tentativa de constituírem-se sujeitos de direitos, uma trajetória de obstáculos que seguiu longo e tortuoso caminho em busca do sentimento de liberdade.

É possível verificar que em determinados períodos a história revela um descompasso e apresenta pontos de grande significância para o movimento de luta dos negros, ainda que em outros momentos, do ponto de vista das conquistas, sejam menos expressivos e escassas possibilidades de mudanças que promovam a garantia de seus direitos e condições de iguais.

Vale ressaltar que, embora a reação da população e dos negros em algumas ocasiões envolveu força física, derramamento de sangue e outros conflitos como as revoltas da Vacina, como manifesto a ordem estabelecida, e, da Chibata, como resistência brasileira ao racismo, 
Artigo original

Hegemonia - Revista Eletrônica do Programa de Mestrado em Direitos Humanos, Cidadania e Violência/Ciência Política do Centro Universitário Unieuro

ISSN: $1809-1261$

UNIEURO, Brasília, número 29, Janeiro a Junho de 2020, pp. 62-84.

denotam, sobremaneira, reflexos de conscientização política do povo fruto das ideias dos defensores intelectuais negros.

Outro aspecto que nos chama atenção e que do nosso ponto de vista caracteriza a negação da cidadania dos negros, foi o tipo de 'liberdade' concedida aos negros escravizados.

Após a formal abolição da escravatura, fica evidenciada essa situação quando o Estado brasileiro implantou políticas de imigração em favor de trabalhadores, de famílias brancas, europeias, reforçando mais uma vez a condição de exclusão e marginalização dos negros juridicamente libertos.

Destarte, os negros foram impedidos de ingressar no mercado de trabalho, além de sofrerem perseguições e sanções nas suas manifestações culturais e religiosas, como a prática da capoeira e o culto ao candomblé, por exemplo.

Há ainda quem afirme que essa prática de imigrar europeus era a tentativa de miscigenação para 'embranquecer' o país.

Diante o exposto, nota-se que foram muitas as lutas travadas por esse grupo social na tentativa de inserção da população discriminada e excluída na então sociedade brasileira póscolonial.

Embora a passos lentos, e sob 'repressão', pois a cada manifestação desse grupo, fosse por parte de um intelectual negro, por exemplo, o Estado enfraquecia o movimento com a criação de leis, proibições a esse segmento da sociedade.

No entanto, tais acontecimentos também revelam que a população negra não era passiva, foram momentos de muita resistência e luta para fazer valer os seus direitos em busca da conquista de cidadania.

Com a promulgação da Constituição de 1988, marcada pelo debate sobre a chamada dívida social, refletida nessa desigualdade que marcava a sociedade brasileira, na escassa distribuição de riqueza derivada do crescimento econômico e na precária cobertura de políticas sociais, firma-se a agenda radical de defesa dos direitos bumanos e dos direitos civis e sociais dos negros. (GUIMARÃES, 2012).

Em face ao marco legal, os últimos anos da década de 80, e em especial na década de 90, muitos movimentos intensificaram-se como bandeira de luta da cidadania e igualdade racial.

Alguns setores do Movimento Negro se articularam para constituírem-se a Coordenação Nacional de Entidades Negras (Conem). Essa organização objetivava se estabelecer como uma central dessas entidades, regatando um pouco do papel desempenhado pelo Movimento Negro Unificado no início de sua fundação. 
Artigo original

Hegemonia - Revista Eletrônica do Programa de Mestrado em Direitos Humanos, Cidadania e Violência/Ciência Política do Centro Universitário Unieuro

ISSN: $1809-1261$

UNIEURO, Brasília, número 29, Janeiro a Junho de 2020, pp. 62-84.

Ademais a discriminação racial e o racismo, como elementos atuantes de restrição à igualdade de oportunidades e alimentando o processo de manutenção da população negra nas piores posições da sociedade brasileira, passaram a ser objeto mais presente em debates e focos de proposições.

Nesse sentido, a discussão ganha visibilidade com a realização da Marcha Zumbi dos Palmares contra o Racismo, pela Cidadania e pela vida, no ano de 1995. O documento elaborado pela Marcha defende a implementação de políticas específicas nos campos da educação, incluindo a capacitação dos professores para lidar com o tema da diversidade racial e com as práticas discriminatórias.

No entanto, as demandas por essas políticas específicas se aprofundaram tão somente com o processo de preparação da participação do Brasil com o documento oficial brasileiro para a III Conferência Mundial de Combate ao Racismo, Discriminação Racial, Xenofobia e Intolerância Correlata ${ }^{3}$ que serve para orientar as políticas públicas de governo.

É reconhecida a responsabilidade histórica do Estado brasileiro "pelo escravismo e pela marginalização econômica, social e política dos descendentes de africanos”. (DAL ROSSO: 2009:9).

Sua consolidação como pauta do Movimento Negro, levou em 2003, à criação da Secretaria Especial de Políticas de Promoção da Igualdade Racial - SEPPIR/PR, órgão vinculado à Presidência da República.

De acordo com a Medida Provisória no 111 , de 11 de março de 2003, convertida na Lei no 10.678, de 23 de maio de 2003, compete a SEPPIR/PR a responsabilidade "[...] pela formulação, coordenação e articulação de políticas e diretrizes para a promoção da igualdade racial e proteção dos direitos dos grupos raciais e étnicos discriminados, com ênfase na população negra".

Também nesse cenário de reivindicações dos movimentos sociais, além da problemática das relações étnico-raciais, como a discriminação e o racismo, a discussão sobre as questões de gênero, da diversidade sexual, surge na pauta do debate dos demais grupos considerados minoritários - mulheres, os grupos LGBTT (lésbicas, gays, transexuais, transgêneros) a exigência por tratamento igualitário.

Neste contexto socio político é de fundamental importância o desenvolvimento de um novo processo de formulação de políticas públicas que atendam de forma equânime e equitativa todos os cidadãos do Brasil.

\footnotetext{
${ }^{3}$ A III Conferência Mundial foi promovida pela ONU e realizada em Durban, na África do Sul, entre 31 de agosto e 7 de setembro de 2001.
} 
Artigo original

Hegemonia - Revista Eletrônica do Programa de Mestrado em Direitos Humanos, Cidadania e Violência/Ciência Política do Centro Universitário Unieuro

ISSN: 1809-1261

UNIEURO, Brasília, número 29, Janeiro a Junho de 2020, pp. 62-84.

Tudo isto está marcado pelo processo de naturalização das diferenças existentes desde os séculos XIX e XX, onde se vinculou à restrição do acesso à cidadania aos diferentes grupos sociais, visão esta que já está ultrapassada em muitos países do mundo.

\section{As Instituições brasileiras}

Conforme relato anteriormente descrito, o Documento Oficial para a III Conferência de Durban, África do Sul, em 2001, responsabilizou o governo brasileiro sobre a negação da cidadania aos negros mediante o processo histórico de escravização. Em face ao contexto, o governo brasileiro estabelece a seguinte proposição, segundo DAL ROSSO (2009),

A adoção de medidas reparatórias às vítimas do racismo, da discriminação racial e de formas conexas de intolerância, por meio de políticas públicas específicas para a superação da desigualdade. Tais medidas reparatórias, fundamentadas nas regras de discriminação positiva prescritas na Constituição de 1988, deverão contemplar medidas legislativas e administrativas destinadas a garantir a regulamentação dos direitos de igualdade racial previstos na Constituição de 1988, com especial ênfase nas áreas de educação, (grifos nossos), trabalho (...). (Brasil, 2001:28-29)

SILVA e ARAÚJO (2011: 495) também retomam as proposições da Carta de Durban e destacam:

99. Reconhece que o combate ao racismo, discriminação racial, xenofobia e intolerância correlata é responsabilidade primordial dos Estados. Portanto, incentiva os Estados a desenvolverem e elaborarem planos de ação nacionais de oportunidades e participação para todos. Através, dentre outras coisas, de ações e de estratégias afirmativas ou positivas; estes planos devem visar a criação de condições necessárias para a participação efetiva de todos nas tomadas de decisão e o exercício dos direitos civis, culturais, econômicos, políticos e sociais em todas as esferas da vida com base na não discriminação.

Nesse sentido, a Lei de Diretrizes e Bases da Educação Nacional, lei nº 9.394/96, em seu artigo 26-A, expressa que uma das ações públicas que busca minimizar as desigualdades raciais e sociais valendo-se da promoção de uma educação antirracista e antidiscriminatória.

O discurso presente é de uma política educacional controversa, pois ao mesmo tempo em que o debate se acirra sobre o discurso da inexistência de racismo no Brasil, com reafirmação da 
Artigo original

Hegemonia - Revista Eletrônica do Programa de Mestrado em Direitos Humanos, Cidadania e Violência/Ciência Política do Centro Universitário Unieuro

ISSN: $1809-1261$

UNIEURO, Brasília, número 29, Janeiro a Junho de 2020, pp. 62-84.

retórica do mito da democracia racial, bem como espaço de igualdade de oportunidades, estudos revelam que nas práticas das relações sociais esse elemento discriminatório ainda se faz presente.

A Lei $\mathrm{n}^{\circ} 10.639 / 2003$ institui a obrigatoriedade do ensino de História da África e da Cultura afro-brasileira. No ano de 2004, o Conselho Nacional de Educação aprovou o Parecer 03/2004 que propõe as Diretrizes Curriculares para a Educação das Relações Étnico-Raciais e para o Ensino de História e Cultura Africanas e Afro-Brasileiras.

Nesse quadro de reparações, como um dos mecanismos de restituição a igualdade de oportunidades, ganha forma a implantação de políticas de ação afirmativa que modifiquem o perfil da universidade brasileira, ainda excludente, para um modelo de educação inclusiva de segmentos estigmatizados, entre os quais os grupos étnico-raciais.

\section{Algoritmos para se conquistar a Eficácia e a Equidade na aplicação das Políticas Públicas}

Do nosso entendimento, faz-se necessário destacar o significado do conceito de políticas públicas referente ao sentido utilizado neste ensaio, para em seguida se fazer uma análise da eficácia e da relevância de sua implantação, como política pública de promoção da igualdade racial.

Segundo CATTANI (2009, apud SANTOS JUNIOR, 2009: 100), política pública se constitui em uma série de ações organizadas como vistas a atender aos interesses públicos, na perspectiva de garantir os direitos sociais e coletivos.

Nesse sentido, o referido autor afirma que “[...] no Estado moderno e seus governos democráticos, o âmbito da política pública é a cidadania, entendida como relação entre Estado e sociedade civil mediada pelos direitos". O que no entendimento de SANTOS JUNIOR (op. cit.) trata-se de uma cidadania restrita, uma vez que atende aos interesses privados e não coletivos.

Ainda nessa linha interpretativa, SANTOS JUNIOR (op. cit.) elucida que o desafio das políticas públicas em um Estado democrático, a exemplo o Brasil, está na sua implantação, na dificuldade em atender as necessidades particulares da sociedade, haja vista o Estado brasileiro se encontrar sob o domínio das "forças de mercado", impostas pela lógica neoliberal do capitalismo. Em suas palavras enfatiza

(...) Portanto, em um ambiente sob o domínio da lógica neoliberal e do Capitalismo Monopolista de Estado (CME), a proposição e a articulação das políticas públicas irão encontrar uma série de entraves que só poderão ser superados e minimizados com a manutenção dos 
Artigo original

Hegemonia - Revista Eletrônica do Programa de Mestrado em Direitos Humanos, Cidadania e Violência/Ciência Política do Centro Universitário Unieuro

ISSN: 1809-1261

UNIEURO, Brasília, número 29, Janeiro a Junho de 2020, pp. 62-84.

movimentos sociais organizados, capazes de manter sua independência política e autonomia diante do capital. (p. 100)

Nesse contexto, os estudiosos buscam em suas análises explicações sobre a viabilização das políticas públicas a partir da organização da sociedade civil sob a ótica de uma nova configuração social, política, econômica no Brasil. Tais percepções acreditam que assim as políticas públicas permitirão romper com as barreiras que separam o Estado da sociedade.

No entanto, esses estudos também afirmam que as demandas apresentadas pela sociedade civil organizada (sindicatos, associações, ONG’s em geral) aos dirigentes públicos, nem sempre são atendidas, face aos recursos destinados a essas exigências serem limitados e por vezes escassas.

O caso aqui em discussão nos remete a seguinte curiosidade: o que representa a implantação dessas políticas para a população brasileira afetada? Qual a sua eficácia? Atende efetivamente ao princípio da igualdade de direito aos grupos excluídos dessa premissa?

Desde a implantação da Constituição de 1988, pautada em princípios democráticos do Estado de direito, um dos preceitos normativos "Dos Direitos e Garantias Fundamentais", acentua a igualdade expressa no artigo $5^{\circ}$ “Todos são iguais perante a lei, sem distinção de qualquer natureza, garantindo-se aos brasileiros e aos estrangeiros residentes no País a inviolabilidade do direito à vida, à liberdade, à igualdade, à segurança e à propriedade [...] e mais adiante proclama o acesso da população a todos os direitos sociais.

No entanto, a instituição normativa por si só, não garante a sua eficácia. Para PIOVESAN (2012: 272), esse discurso da igualdade formal é insuficiente; pois tratar o indivíduo de forma genérica, geral e abstrata pressupõe a negação do direito de ser atendido em suas particularidades.

Há, portanto, a necessidade de especificação do sujeito de direito, que passa ater um tratamento especial. Nesse panorama, a autora exemplifica que “[...] a população afrodescendente, as mulheres, as crianças e demais grupos devem ser vistos nas especificidades e peculiaridades de sua condição social. Ao lado da igualdade, surge também, como direito fundamental, o direito à diferença".

PIOVESAN (op. cit.) ainda faz uma crítica à concepção de igualdade, na conquista do direito e respeito à diferença, como sistema especial de direitos humanos, e, ressalta os princípios das três vertentes: 
Artigo original

Hegemonia - Revista Eletrônica do Programa de Mestrado em Direitos Humanos, Cidadania e Violência/Ciência Política do Centro Universitário Unieuro

ISSN: 1809-1261

UNIEURO, Brasília, número 29, Janeiro a Junho de 2020, pp. 62-84.

[...] a) a igualdade formal, reduzida à fórmula "todos são iguais perante a lei" (que , ao seu tempo foi crucial para abolição de privilégios); b) a igualdade material, correspondente ao ideal de justiça social e distributiva (igualdade orientada pelo critério socioeconômico); e c) igualdade material, correspondente ao ideal de justiça enquanto reconhecimento de identidades (igualdade orientada pelos critérios gênero, orientação sexual, idade, raça, etnia e outros). (p. 272)

SILVA, A. et all (2009), ao fazer uma avaliação das ações e compromissos do governo brasileiro com relação à políticas de implantação da igualdade racial, a SEPPIR ressalta que a ausência de resultados mais expressivos não se aplica pela falta de orientações.

Assinala que no ano de 2003, com o lançamento da Política Nacional de Promoção da Igualdade Racial, tendo em vista a redução no quadro das desigualdades, destaca a qualificação de gestores públicos e de professores, a adoção de cotas no ensino superior e no mercado de trabalho, bem como o desenvolvimento de programas de saúde para a população negra, entre outras orientações.

No entanto ao avaliar as ações e compromissos e adesões brasileira no cenário internacional, que aborda o tema do racismo e da discriminação, o autor destaca duas manifestações internacionais de teor crítico, em 2006, em relação à atuação do governo brasileiro. Em suas palavras

Em 2006, a Organização dos Estados Americanos (OEA), por meio de sua Corte Interamericana de Direitos Humanos (DIDH), condenou o Estado brasileiro por ter negado a uma vítima de racismo a garantia de proteção judicial, assim como por ter violado o seu direito de igualdade perante a lei. (2009:39)

Ainda, segundo SILVA (op. Cit.), o Relatório nº 66/2006 da CIDR/OEA não apenas condena o Estado brasileiro por omissão e desrespeito ao direito de acesso à Justiça, como avalia a legislação nacional que regulamenta o dispositivo constitucional que criminaliza os atos de racismo. 
Artigo original

Hegemonia - Revista Eletrônica do Programa de Mestrado em Direitos Humanos, Cidadania e Violência/Ciência Política do Centro Universitário Unieuro

ISSN: $1809-1261$

UNIEURO, Brasília, número 29, Janeiro a Junho de 2020, pp. 62-84.

5. Diagnóstico da situação social e política, visando a satisfação da sociedade

É interessante pontuar alguns elementos que configuram este cenário do cumprimento de políticas públicas em resposta às demandas sociais postas, em especial pelo desejo de tratamento à igualdade de direitos sociais, como exercício pleno de cidadania.

$\mathrm{Na}$ nossa ótica, o nível de satisfação a que as políticas públicas têm proporcionado à sociedade brasileira de maneira geral, é um elemento balizador com vistas a oportunidades iguais a futuras gerações.

Portanto, quando se direciona o olhar para o cumprimento das políticas públicas dessa natureza, caracterizada por processos históricos conflitantes, o sistema social nos mostra entre outros aspectos, que a dimensão política figurou uma seara de contrastes, marcada pelas relações de poder e a supremacia de determinados grupos sociais.

Alguns aspectos que ilustram bem essa situação típica de desigualdades sociais pode-se retomar o processo histórico de luta pela igualdade racial em que as populações negras e indígenas têm travado nas últimas décadas.

Embora as legislações internas figurem as normas previstas nas convenções e acordos na comunidade internacional, a implantação de políticas públicas em consonância com prática da igualdade de direitos ainda deixa a desejar. O Estado brasileiro ainda presencia conflitos dessa natureza.

As ações afirmativas, a igualdade de direitos aos homossexuais, às mulheres, às comunidades indígenas, por exemplo, ainda é um assunto que causa desconforto e a não aceitação ecoa em muitos fóruns de debates. Nota-se no discurso teórico de alguns pesquisadores certo descontentamento com essa política, assim como no posicionamento preconceituoso e discriminatório porte de alguns representantes da sociedade no parlamento.

Caso semelhante é a demarcação de terras para a população quilombola e também para as comunidades indígenas, garantida pelo reconhecimento de propriedade na Constituição de 1988, ainda se configura em processo lento e o modelo adotado não atende às reivindicações dos grupos e, quando sofrem problemas de judicialização, o conflito se instala entre esses grupos e os setores agrários da sociedade e órgãos estatais. 
Artigo original

Hegemonia - Revista Eletrônica do Programa de Mestrado em Direitos Humanos, Cidadania e Violência/Ciência Política do Centro Universitário Unieuro

ISSN: 1809-1261

UNIEURO, Brasília, número 29, Janeiro a Junho de 2020, pp. 62-84.

6. Conclusões

Face ao exposto, há que se considerar que a participação política dos brasileiros no processo de instituição da cidadania, foi um processo lento e marcado por um cenário de desigualdade na luta de forças contrárias. Nota-se que a luta pela implantação dos direitos sociais, civis e políticos sofreram restrições mediante a violência física e repressões nos conflitos registrados em vários períodos da nossa história, bem como a violência simbólica no tratamento das relações estabelecidas por um segmento social que detinha privilégios.

Com relação à população negra, como segmento excluído nesse contexto social, observase que, mesmo alcançando a igualdade jurídica com a Abolição, mantinha-se não só a desigualdade econômica e social entre brancos e negros, mas ainda a antiga ideologia que definia bem a diferença entre os dois grupos e reservava ao negro uma posição de submissão.

Ilustra bem esse nosso entendimento o registro da história que do momento formal da Abolição da Escravidão aos anos de 1930, desenvolveu-se uma teoria racial que considerava qualquer tipo de mestiçagem como algo que atrapalhava o progresso da nação.

Por outro lado, o povo negro não foi passivo aos acontecimentos, e há de se reconhecer que a trajetória de resistência e luta do negro traz reflexos para os nossos dias nas manifestações de um envolvimento mais amplo dos movimentos sociais e também do Movimento Negro.

O protagonismo maior passa a ser dos movimentos sociais, ainda que o Estado se mantenha central. É na ordem de garantia dos direitos individuais e coletivos que prospera o reconhecimento da singularidade étnica.

No que diz respeito à implantação de políticas de promoção da igualdade racial, como perspectiva de sujeitos de direitos à população excluída, em nossa avaliação foi um grande avanço que descortinou um passado opressor e minimamente tem reparado essa dívida social.

Não obstante, ainda continuamos presenciando um cenário de desigualdades sociais, a falta de uma política capaz de prevenir e eliminar as desigualdades sociais, o exercício pleno da cidadania, haja vista a cultura política de não fazer valer os direitos civis e coletivos, mesmo por decorrência da estrutura jurídico-política do Estado do tipo patrimonial, que se pode constatar na compreensão de 'o que é direito do cidadão é dever do Estado'.

Bibliografia

ARISTÓTELES. Política. 3. ed. Brasília: Editora Universidade de Brasília, 1997. 
Artigo original

Hegemonia - Revista Eletrônica do Programa de Mestrado em Direitos Humanos, Cidadania e Violência/Ciência Política do Centro Universitário Unieuro

ISSN: 1809-1261

UNIEURO, Brasília, número 29, Janeiro a Junho de 2020, pp. 62-84.

BOBBIO, Norberto. A era dos direitos. . Tradução de Carlos Nelson Coutinho; apresentação de Celso Lafer. Nova Ed. RJ: Elsevier, 2004.

BRASIL. [Constituição de 1988]. Constituição da República Federativa do Brasil: Supremo Tribunal Federal. Brasília: Supremo Tribunal Federal, 2007.

CARVALHO, José Murilo de. Cidadania no Brasil: o longo caminho. 13. ed. RJ: Civilização Brasileira, 2010.

CHÂTELER, François. História das ideias políticas. Tradução, Carlos Nelson Coutinho,RJ Zahar,ed, 2000.

DALLARI, Dalmo de A. Direitos humanos e cidadania. 2. ed. SP: Moderna, 2004.

DAL ROSSO, Sadi. (org). Políticas para promoção da igualdade racial no Brasil: o papel da SEPPIR. Goiânia: FUNAPE/ Programa de Direitos Humanos da UFG, 2009.

FONSECA, Vicente - Engenharia de Políticas Públicas Transparentes - Editora CRV - Curitiba -2019 .

GALVÃO, A. C. F. Política de Desenvolvimento Regional e Inovação: Lições para o Brasil da experiência Europeia. Campinas, 2003. 223p. Tese. (Doutorado em Economia) - UNICAMP, IEU.

Desenvolvimento regional e inovação como instrumentos fundamentais para o desenvolvimento brasileiro. Revista Parcerias Estratégicas. Brasília, Centro de Gestão e Estudos Estratégicos, n. 20, parte 2, pp. 593 - 619. jun. 2005.

A Política Brasileira de Desenvolvimento Regional e o ordenamento territorial. In: DINIZ, Clélio campolina, (org). Políticas de Desenvolvimento Regional: desafios e perspectivas à luz das experiências da União Europeia e do Brasil. Brasília, Editora da Universidade, 2007. pp. 327-351.

GOULART, George L. - Os Atores em Políticas Públicas http://georgelucasgoulart.blogspot.com.br/2016/03/os-atores-em-politicas-publicas.html 2016.

GUERRA, Sidney. Direitos Humanos Curso Elementar.SP: Saraiva, 2013.

GORDON, A. - Análise de Política que abrange um amplo espectro. Free Press. NYC USA, 1977 
Artigo original

Hegemonia - Revista Eletrônica do Programa de Mestrado em Direitos Humanos, Cidadania e Violência/Ciência Política do Centro Universitário Unieuro

ISSN: 1809-1261

UNIEURO, Brasília, número 29, Janeiro a Junho de 2020, pp. 62-84.

GUIMARÃES, R. A Diáspora: Um Estudo Exploratório sobre o Deslocamento Geográfico de Pesquisadores Brasileiros na Década de 90. DADOS - Revista de Ciências Sociais, Rio de Janeiro, Vol. 45, no 4, 2002, pp. 705-750.

GUIMARÃES, Antonio Sérgio Alfredo. Cidadania e Retóricas Negras de Inclusão Social In Revista Lua Nova, SP, 85: 13-40, $2012 . \quad$ Disponível em<http:/ /www.scielo.br/scielo.php?pid=S010264452012000100002\&script=sci_arttext> Acesso em 3 de junho de 2013.

HALL, Peter A. and TAYLOR, Rosemary C. R.. As três versões do neo-institucionalismo. Lua Nova. 2003, n.58, pp. 193-223.

HAM, Cristopher; HILL Michael. The policy process in the modern capitalist state. Londres, 1993. HATAB, Lawrence - Genealogia da Moral de Nietzsche - Editora MADRAS - SP - 2008 LENZA,Pedro - Direito Constitucional Esquematizado. 16ª Edição. São Paulo: Saraiva, 2012. HECLO, H. Review article: policy analysis. British Journal of Political Science. 1972. HENRY, Gary T. How modern democracies are shaping evaluation and the emerging challenges for evaluation. American Journal of Evaluation, v. 22, n. 3, p. 419-429,Sept. 2001.

HILL, M. New agendas in the study of the policy process. Harvester Wheatsheaf, Great Britain, 1993.

HOGHOOD, B.; GUNN, L. Policy analysis for the real world. Oxford: Oxford University Press. 1984.

HOLANDA, A. “Apresentação". In: Rocha Neto, I. Ciência, Tecnologia e Regionalização.

Descentralização, Inovação e Tecnologias Sociais. Rio de Janeiro: Garamond, 2005.

HOWLET,M; RAMES,M e PERL,A. - Política Pública : seus ciclos e subsistemas - Elsevier e Campus - RJ - 2013.

HUNTINGTON, Samuel P. A terceira onda. São Paulo : Ática, 1994.

IBGE. http://www.ibge.gov.br. Acesso em: 6 de junho de 2012

JOBERT, Bruno; MULLER, Pierre. L'Etat en action. Paris: PUF, 1987.

KEINERT, Fábio Cardoso; SILVA, Dimitri Pinheiro. A gênese da ciência política Brasileira. Tempo soc., São Paulo, v. 22, n. 1, jun. 2010 . Disponível em <http://www.scielo.br/scielo.php?script=sci_arttext\&pid=S0103-207020100001

00005\&lng=pt\&nrm=iso $>$. acessos em 16 jun. 2012. http://dx.doi.org/10.1 590/S 010320702010000100005.

LASSWELL, H. The policy orientation. In D. Lerner and H. Lasswell (eds.). The Policy Sciences. Stanford: Stanford University Press,, 1951. 
Artigo original

Hegemonia - Revista Eletrônica do Programa de Mestrado em Direitos Humanos, Cidadania e Violência/Ciência Política do Centro Universitário Unieuro

ISSN: 1809-1261

UNIEURO, Brasília, número 29, Janeiro a Junho de 2020, pp. 62-84.

LEÃO, Renato Zerbini Ribeiro. O respeito à dignidade da pessoal humana: reflexõesà luz do direito internacional dos direitos humanos. in IV Curso Brasileiro interdisciplinar em Direitos Humanos. O Respeito à Dignidade da Pessoa Humana, coordenadores: Antônio Augusto Cançado Trindade e César Barros Leal. p.510 e 511 Fortaleza 2015. Disponível em < http://ibdh.org.br/biblioteca-virtual/> Acesso em 09 de outubro de 2017.

LEHER, Roberto. Educação no governo de Lula da Silva: a ruptura que não aconteceu. In: MAGALHÂES, João Paulo de Almeida et al. Os anos Lula, contribuições para um balanço crítico 2003-2010. Rio de Janeiro: Garamond, 2010. p.369-412.

LINDBLOM, C. The intelligende of democracy. New York: The Free Press, 1965; e Still muddling, not yet through. Public Administration Review, 39, 1979.

LINDBLOM, Charles E. O processo de decisão política. Brasília: Editora da Univ. de Brasília, 1981.

LOBO, Thereza. Avaliação de processos e impactos em programas sociais: algumas questões para reflexão. In: RICO, Elizabeth Melo (Org.). Avaliação de políticas sociais: uma questão em debate. São Paulo: Cortez, 1998. p. 75-84.

LOVETT, Frank. Uma Teoria da Justiça de John Rawls. SP: Penso Editora LTDA. Explorando grandes obras., 2011.

MARTINS, Ives Gandra da Silva - A Separação dos Poderes no Brasil - Instituto dos Advogados de São Paulo - SP - 2015.

MOISES, José Álvaro. Cultura política, instituições e democracia: lições da experiência brasileira. Rev. bras. Ci. Soc. [online]. 2008, vol.23, n.66, pp. 11-43..

MOON, M.J.;INGRAHAM, P. Shaping administrative reforms and governance: an examination of the political nexus triad in three Asian countries. Governance, v. 11, n. 1, p. 77-100, 1998.Rio de Janeiro. Anais... Rio de Janeiro: Anpad, 2004. p.1-14. CD-ROM.

NORTH, Douglass. Institutions, Institutional Change and Economic Performance. Cambridge: Cambridge University Press. 1990

NUNES, Denise (Red.). Ética e pluralidade cultural. Diário Catarinense, Caderno Ensino a Distância, n. 4, Curso de Aprimoramento Profissional, Florianópolis.

O’ DONNELL, Guilhermo. Poliarquias e a (in)efetividade da Lei na América Latina. In: Mendes, J., O’Donnell G., \& Pinheiro, S. (orgs.): Democracia, Violência e Injustiça. O Não-Estado de Direito na América Latina, São Paulo, Paz e Terra, 2000. PAIM, Antônio Ferreira. A Questão Democrática. São Paulo: Instituto Humanidades, 2010. 
Artigo original

Hegemonia - Revista Eletrônica do Programa de Mestrado em Direitos Humanos, Cidadania e Violência/Ciência Política do Centro Universitário Unieuro

ISSN: 1809-1261

UNIEURO, Brasília, número 29, Janeiro a Junho de 2020, pp. 62-84.

PESSOTI, Gustavo Casseb; SAMPAIO, Marcos Guedes Vaz; SPÍNOLA, Noélio Dantas. Incentivos fiscais e a política de atração industrial na Bahia: uma análise pós 1990. Revista Desenbahia. Salvador-BA: Desenbahia, v.5, n.8, p.7-23, mar. 2008.

PIOVESAN, Flávia. Temas de Direitos Humanos. 5. ed. SP: Saraiva, 2012.

PRADO, Caio Jr - Evolução Política do Brasil -Editora brasiliense - São Paulo - 1999.

PRELÓT, Marcel. La Ciência Política. 6.ed. Buenos Aires: EUDEBA, 1972.

PROMINP. http://www.prominp.com.br. Acesso em 4 de junho de 2012.

PRZEWORSKI, Adam. O Estado e o cidadão. in Luís Carlos Bresser Pereira, Jorge Wilheim, Lourdes Sola, (orgs.). Sociedade e Estado em Transformação. São Paulo: Editora da UNESP,Brasilia: ENAP, 1999.

RANDS, Alexandre. Desigualdades regionais no Brasil: Natureza, causas, origens e soluções. Rio de Janeiro: Elsevier, 2011.

REIS, Elisa P. Reflexões leigas para a formulação de uma agenda de pesquisa em políticas públicas. Revista Brasileira de Ciências Sociais, São Paulo, v. 18, n. 51, p. 11-14, fev. 2003.

ROCHA, Cármen Lúcia Antunes. Ação afirmativa: o conteúdo democrático do princípio da igualdade jurídica. revista de informações legislativa, V. 33, n 131, p. 283_295, Jul/Set 1996; Revista Trimestral de Direito Público, n. 15, p. 85-99, 1996 | Gênesis : Revista de Direito Administrativo Aplicado, v. 3, n. 10, p. 649-664, jul./set. 1996.disponível em < http://www2.senado.leg.br/bdsf/handle/id/176462> acessado em 08 de outubro de 2017.

RONCA, Antonio Carlos Caruso; RAMOS, Mozart Neves. Da CONAE ao PNE - 2011-2020: Contribuições do Conselho Nacional de Educação. São Paulo: Moderna, 2012.

ROULAND, Norbert. Roma, democracia impossível?: os agentes do poder na urbe romana. Brasília. Editora Universidade de Brasília, 1997. CAPÍTULO I.

RUEL, Thiago Santos. Lobby, Grupos de Pressão e Grupos de Interesses. Disponível em: $<$ http://www.craes.org.br/arquivo/artigoTecnico/Lobby_28.pdf > . Acessado em 19 de julho de 2016.

SAMPAIO, J. e ARAÚJO, J. L. - Artigo Científico - Análise das políticas públicas: uma proposta metodológica para o estudo no campo da prevenção em Aids -Departamento de Saúde Coletiva. Centro de Pesquisa Ageu Magalhães, Campus da Universidade Federal de Pernambuco - 2015. 
Artigo original

Hegemonia - Revista Eletrônica do Programa de Mestrado em Direitos Humanos, Cidadania e Violência/Ciência Política do Centro Universitário Unieuro

ISSN: 1809-1261

UNIEURO, Brasília, número 29, Janeiro a Junho de 2020, pp. 62-84.

SANDEL, Michael J. Justiça - O que é fazer a coisa certa. [tradução Heloisa Matias e Maria Alice Máximo] 13ª ed. Civilização Brasileira. RJ: 2014

SANTOS, Wanderley. O Ex-Leviatã brasileiro. Rio de Janeiro, Civilização Brasileira. 2006

SANTOS, Andreia R.dos - A Teoria do Programa e seus Múltiplos Usos:Construindo Referências para a Avaliação de Desempenho do PRONATEC - SOF - Brasília -2013.

SANTOS JR, Oswaldo de O. Estado contemporâneo e políticas públicas. In Do global ao local: tensões e conflitos no espaço urbano. Praun, Luci. (org). Universidade Metodista de São Paulo. 2. ed. SBC: Ed. do Autor, 2009.(pp. 91-103).

SARTORI, Giovanni. A teoria da democracia revisitada. São Paulo: Editora Ática. 1994. (Vol. I: O debate contemporâneo).

SCHUMPETER, Joseph A. Capitalismo, socialismo e democracia. Rio de Janeiro: Fundo de Cultura, 1961

SILVA, Adailton. et all. Entre o racismo e a desigualdade: da Constituição à promoşão de uma política de igualdade racial (1988-2008). In JACCOUD, Luciana. (org.). A Construção de uma Política de Promoção da Igualdade Racial: uma análise dos últimos 20 anos. Brasília: Ipea, 2009.

SILVA, Paulo V. B. da. e ARAÚJO, Débora C. de. Educação em Direitos Humanos e Promoção da Igualdade Racial. In Revista Linhas Críticas, Brasília, DF, n. 34, p. 483-505, set./dez. 2011. SILVA, José Afonso da. Curso de Direito Constitucional Positivo. 26a Edição. São Paulo: Malheiros, 2006

SILVA, Pedro Luiz Barros e MELO, Marcus André Barreto de - O Processo de Implementação de Políticas Públicas no Brasil: Características e Determinantes da Avaliação de Programas e Projetos - UNICAMP - NEPP - SP - 2000

SILVA, Pedro Luiz Barros; COSTA, Nilson do Rosário. A avaliação de programas públicos: reflexões sobre a experiência brasileira. Brasília: Ipea, 2002.

SILVA, E. F. C. A emergência de um novo paradigma nas políticas de formação de recursos humanos em ciência e tecnologia no Brasil: Uma análise do Programa.

SILVA, S. T. Resenha. Política de Desenvolvimento Regional e Inovação: Lições da Experiência Europeia. Revista Paranaense de Desenvolvimento, Curitiba, n. 110, pp.141-146, jan./jun. 2006.

SOUZA, Celina. "Estado do campo" da pesquisa em políticas públicas no Brasil. Revista Brasileira de Ciências Sociais, São Paulo, v. 18, n. 51, p. 15-20, fev. 2003.

SPELLER, Paulo; FILHO, Naomar Monteiro de Almeida; NADER, Rosa Maria. O Potencial das Políticas Educacionais e Tributária para o desenvolvimento com equidade. In: RONCA, 
Artigo original

Hegemonia - Revista Eletrônica do Programa de Mestrado em Direitos Humanos, Cidadania e Violência/Ciência Política do Centro Universitário Unieuro

ISSN: 1809-1261

UNIEURO, Brasília, número 29, Janeiro a Junho de 2020, pp. 62-84.

Antônio Carlos Caruso; RAMOS, Mozart Neves. Da CONAE ao PNE - 2011-2020: Contribuições do Conselho Nacional de Educação. São Paulo: Moderna, 2012.p.15-36.

SOUZA, Rose Mara Viudal de. - Lobby no Brasil regulamentado e a democracia participativa. Disponível em: http://www.compolitica.org/home/wpcontent/uploads/2011/01/rose_vidal.pdf

SCHWARTZMAN, S. Um Espaço para a Ciência: A formação da comunidade científica no Brasil. Brasília: Ministério da Ciência e Tecnologia. 2001.

STEPAN, Alfred. Para uma Nova Análise Comparativa do Federalismo e da Democracia: Federações que Restringem ou Ampliam o Poder do Demos. [Toward a new comparative analysis of democracy and federalismo: demos-constraining and demos-enabling federations]. Revista dados vol. 42 n.2 Rio de Janeiro, 1999.

THEIS, I. M. e DAGNINO, R. P. Política científica e tecnológica e desenvolvimento geográfico desigual no Brasil. In: VII Jornadas Latino-americanas de Estudos Sociais da Ciência e da Tecnologia. Rio de Janeiro. 